\title{
Continuing Education through COVID-19 Crisis in the United Kingdom: A Swiss Trainee Abroad
}

\author{
Alicja Zientara ${ }^{1}$ \\ ${ }^{1}$ Department of Cardiac Surgery, Royal Brompton and Harefield \\ National Health Service Foundation Trust, London, United Kingdom \\ of Great Britain and Northern Ireland \\ Thorac Cardiovasc Surg Rep 2021;10:e25-e29.
}

\begin{abstract}
Address for correspondence Dr. med. Alicja Zientara, Department of Cardiac Surgery, Royal Brompton and Harefield National Health Service Foundation Trust, Sydney street, London SW3 6NP, London SW3 6NP, United Kingdom of Great Britain and Northern Ireland (e-mail: alicja_zientara@web.de).
\end{abstract}
Abstract
Keywords
- cardiac
- education
- all levels
- history

The work has been awarded in July 2020 with the "Special Swiss Young Cardiac Surgeon Award 2020" by the Swiss Society of Cardiac Surgery (Schweizerische Gesellschaft für Herz- und thorakale Gefässchirurgie [SGHC-SSCC]) and reflects a personal perspective from a Swiss trainee experiencing the novel coronavirus disease 2019 (COVID-19) pandemic during her fellowship in London.

\section{Week Zero: COVID-19 Arrives}

March 3, 2020. Is my coronary artery bypass graft (CABG) patient positive? Is the X-ray show an ordinary hospitalacquired pneumonia or is it the new virus? Are we exacerbating without a robust reason? Very soon we will find out that we were not.

In the meantime, news and social media explode with continuous horror scenarios located in China and Northern Italy. Eventually, we all find ourselves under the politically announced lock down (March 18, 2020) traveling to work as the only people who are allowed to move freely using the public transport for London. The annual meeting of the national society of cardiothoracic surgeons (SCTS) at the end of March is cancelled. The major question is whether we already have positive patients on the wards without being aware. But tests are not available for around 70 patients and large rooms are with up to 10 patients in a row. Also, we heard in the news that there is not enough personal protective equipment (PPE). Can this be true?

Harefield Hospital as a highly specialized cardiothoracic center with an active transplant unit has no emergency department and patients are mainly well diagnosed in advance when referred from peripheral hospitals. One regis$\operatorname{trar}$ (Oberarzt) operates with one consultant twice or thrice per week continuing with practical education due to the current level of technical skills. Some of us are more senior operating own cases, while the consultant stays in the operating theater. A very valuable time to progress and continue personal education.

Suddenly, the disease becomes apparent and the first novel coronavirus disease 2019 (COVID-19) patient is transferred to the catheterization (cath) laboratory suffering from a heart attack. It is unquestionable that we cannot carry on with our daily business after further transfers of patients in respiratory failure with the need for intensive care therapy. The following day security staff arrives who asks for our IDs in the morning and controls the hospital pathways. One cath laboratory and one theater become COVID-19 areas with a negative air pressure including full staff protection (-Fig. 1). All meetings and operations are cancelled with immediate effect. Crash courses in intubation and ventilator settings are mandatory and electronic literature is provided to refresh our intensive care knowledge, in case the hospital runs out of experts. The anesthetic team gets ready for emergency intubation scenarios and builds up small teams with qualified doctors for quick intubation not only on intensive therapy unit (ITU) but also on the normal ward. Are surgeons also going to be send to ITU? received

November 7, 2020

accepted

November 13, 2020
DOI https://doi.org/

10.1055/s-0040-1722708. ISSN 2194-7635. (c) 2021. The Author(s).

This is an open access article published by Thieme under the terms of the Creative Commons Attribution-NonDerivative-NonCommercial-License, permitting copying and reproduction so long as the original work is given appropriate credit. Contents may not be used for commercial purposes, or adapted, remixed, transformed or built upon. (https://creativecommons.org/ licenses/by-nc-nd/4.0/) Georg Thieme Verlag KG, Rüdigerstraße 14, 70469 Stuttgart, Germany 


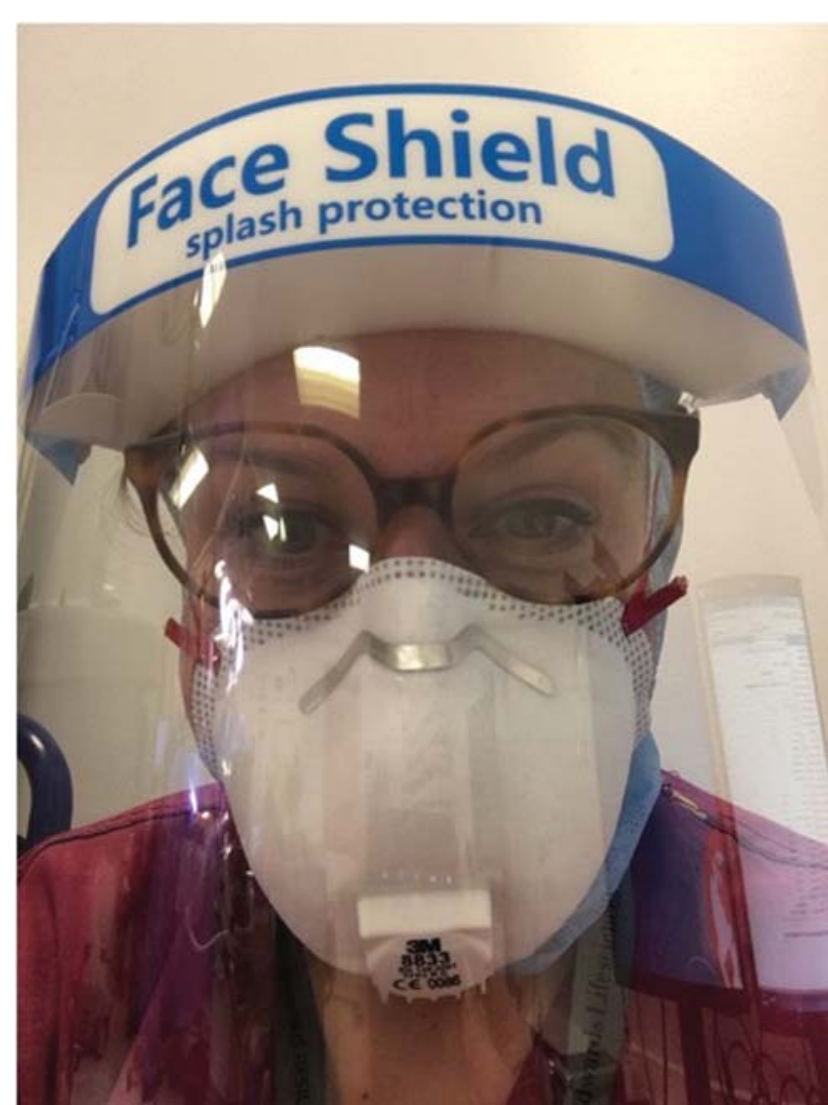

Fig. 1 Before a type-A-dissection repair in a suspected COVID-19positive patient: full PPE is mandatory for every patient without a test result. In patients with two negative tests and a normal chest $C T$, only FFP mask is required during intubation and sternotomy. COVID-19, novel coronavirus disease 2019; CT, computed tomography; FFP, filtering facepiece particle; PPE, personal protective equipment.

\section{Continuing Operations: A Sigh of Relief}

During the following 2 weeks, the decision is made that our hospital in West London and one other hospital in the East (St. Bartholomew hospital) will continue to provide cardiac and thoracic surgery for a population of around 7 million people who need urgent treatment. Elective procedures are on hold and rediscussed, if the health of the patient deteriorates. The cardiothoracic registrars receive a new rota covering also the high dependency unit (HDU), as there might be no intensive care registrars available due to the busy shifts. The junior doctors are relocated to other wards. We do not distinguish between surgical, cardiological, and respiratory junior doctors anymore. However, the main task of the cardiothoracic registrars stays the treatment and expertise in their own field of specialty, at least in our hospital. My colleagues in other cardiothoracic units across London move to ITU leading the ward round, proning patients, inserting installations and wires, and taking care of the ones' who need extracorporeal membrane oxygenation (ECMO) support. Are we the lucky ones in the crisis situation compared with the rest of London? And how shall we decide who is eligible for an operation and who has to wait?

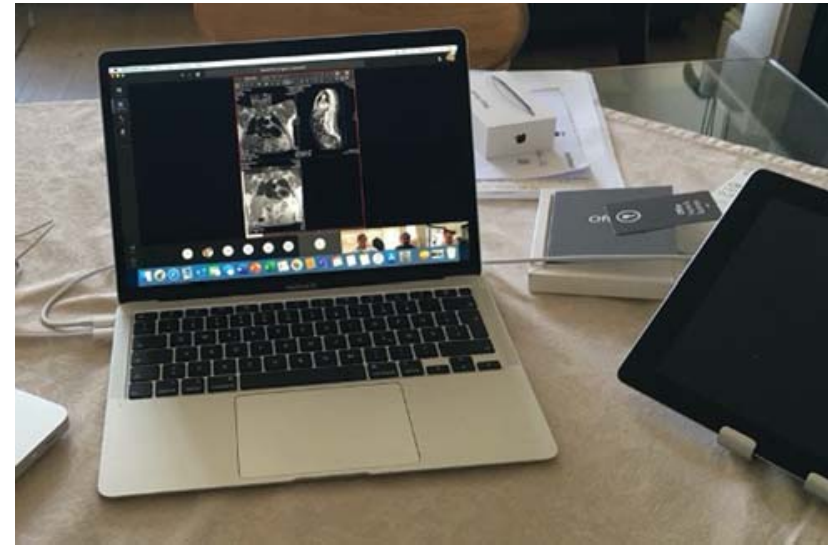

Fig. 2 Working from home: the online cardiothoracic hub meeting, also on Saturdays and Sundays. Patients are short listed for urgent presentations.

\section{Optimizing Communication: The Daily MS Zoom Call}

To provide a comprehensive care for all patients on the waiting list and for all emergencies of West London, daily conference calls are held and documented with an individual plan. Beforehand, nurses and doctors call the patients on the waiting list asking about the current symptoms and documenting who needs an urgent operation. Also, cardiologists from peripheral hospitals take part in the discussions referring their patients directly with a quick summary of the medical history. This immediate communication pathway is new as we mainly used to get the information from the allocated surgeon who saw the patient earlier in clinic and already made a treatment plan. Imaging specialists are available during the call supporting the discussion with the current investigations. ITU doctors inform about the up-to-date situation and available beds. The registrars are also invited to join and do so regularly. MicrosoftTeams, 10 a.m. in the morning becomes the breakfast routine to all of us (-Fig. 2 ).

The two predominant aspects of these calls shift from a simply interdisciplinary calculation of risks to (1) urgency and (2) availability of the treatment. Interventional procedures become an attractive option in situations where prolonged ITU stay is expected. A new challenge for this growing specialty which can demonstrate their significance under unexpected circumstances. For instance, the MitraClip becomes an option to bridge patients after the rupture of the papillary muscle giving them a chance for off-loading until operation.

\section{Collaboration Live in Theaters}

As our affiliated hospital in the middle of London becomes an ECMO center for the severely ill patients, the surgeons from the Royal Brompton hospital are also allocated to Harefield to support with emergencies and the dissection rota. While the Brompton registrars continue working on ITU, our team receives the opportunity to get to know new surgeons, each one using a different technique for standard and emergency cases which turned out to be a more than valuable 
experience. On the one hand, it looks a bit overcrowded and like a lot of surgeons performing surgery in a tiny place. But on the other hand, it is hard to reminiscent the time when there was so much expertise concentrated in one place such as minimal invasive valve surgery, hybrid CABG, suture-less valves, and the good old standard.

\section{Theoretical Training: Electronic Pathways}

Usually, the cardiothoracic trainees have 1 hour of protected time per week for a teaching session which is mainly prepared by us covering examination-relevant topics or discussing current literature. Alike other meetings, also the teaching was held for around 2 weeks. As a result of the successful daily case discussions, we set up the electronic teaching also through Microsoft-Teams ${ }^{\mathrm{TM}}$ which led to the attendance of numerous participants. Also, our consultants found themselves in the online meeting starting vivid discussions. Another beneficial effect is that both sides, Harefield and Brompton, found the common interest in continuing the theoretical education by providing highquality meetings accompanied by expert discussions. Last but not least, our presentations for the SCTS found a new home and could be shown during the sessions. The registrars and junior doctors get to know the research output of the other hospital and find inspiration for their own work.

\section{Research and Data Management}

Experience first in the thoracic team and later also in the cardiac team showed lethal courses in patients where the COVID-19 status was unclear and later confirmed to be positive. The patient data collection system implemented therefore additional pre- and postoperative parameters to distinguish between patients who were found to be infected by the virus to investigate the outcome.

The initial pathway to surgery were two negative tests and a chest computed tomography (CT) without specific changes. Patients without symptoms but a positive test waited for their treatment until the test results were negative. From the data, we will get to know, if these precautions potentially saved lives and how decision-making for or against interventional treatment has influenced on the outcome. Also, international collaboration in the sense of a wider data collection might be an interesting perspective.

\section{Ethical Considerations: Not Only for the Individual but also for Their Families}

The care of many patients has been delayed due to COVID-19 leading to prolonged waiting time and logistical challenges in the planning. Patients in hospital who were tested positive initially waited 2 weeks for the treatment without the chance to go home as the infection risk was too high for the household.

The ITU even faced more dramatic problems than the doctors on the ward. Decisions had to be made regarding continuation of therapy for patients in more than 20 ITU beds without the direct contact to the relatives as no visitors were allowed in the entire hospital. To involve the family in the decision-making and keep them informed about the current status of their loved ones, ITU nurses organized a face time call schedule to provide the daily communication between the patients and their families. Also, if therapy was discontinued, relatives were with the patient through the last minutes and could accompany them on their last way.

\section{Wellbeing and Support at Work}

Despite rapidly changing rotas and unpredictable theater schedules Harefield hospital has been surrounded by amazing people and coworkers who carried each of us through uncertain times. From the beginning, the canteen offered free food and was exclusively opened for National Health Service staff. The supply with free food from restaurants was unbelievable and we never had to worry about a warm meal in the middle of the night. The private patient lounge was turned into the wellbeing lounge providing space to rest, having a snack or a drink, or simply close the eyes for few minutes (-Figs. 3 and 4). Also, it became a place between ITU and normal ward which gave us the chance to have a quick chat and update each other. We also never had to worry about transport to or from work. Patient transport provided a free transfer service for those who were not able to reach Harefield hospital without public transport.

\section{What Switzerland Can Adapt for a Better Training: Questions of the SGHC}

\section{How Can the Seniors Support Us, Where Are the Problems?}

Keep the young surgeons informed. Fortunately, we had the luck to receive daily e-mails about changes in the departments and from our consultants about further plans. However, in other hospitals, young surgeons felt lost without information regarding their contracts, the training continuation, and the salary.

Do not forget to involve the young surgeons in the decision-making process and the management to navigate through the crisis. Logistical planning of health care and the will to overcome boarders, thinking, and acting out of the box are essential to find the best possible solution for the patients and also for the management of a department.

\section{How Did the Training/Education Change? (Does It Have an Impact on Your Formation?)}

Theoretical education went online and has been shared between two centers. I can imagine that this new set up will stay for longer to share research, examination, education, and journal clubs. Also, the attendance of the consultants increased significantly as Microsoft-Teams ${ }^{\mathrm{TM}}$ makes it easy to join.

Interestingly, the daily case sessions at 10 a.m. offered a fantastic addition to the normal teaching as we were able to ask questions through the chat. Trainees were more active to share their ideas online asking about revascularization techniques, interventional options, and timing of operation. Also, 


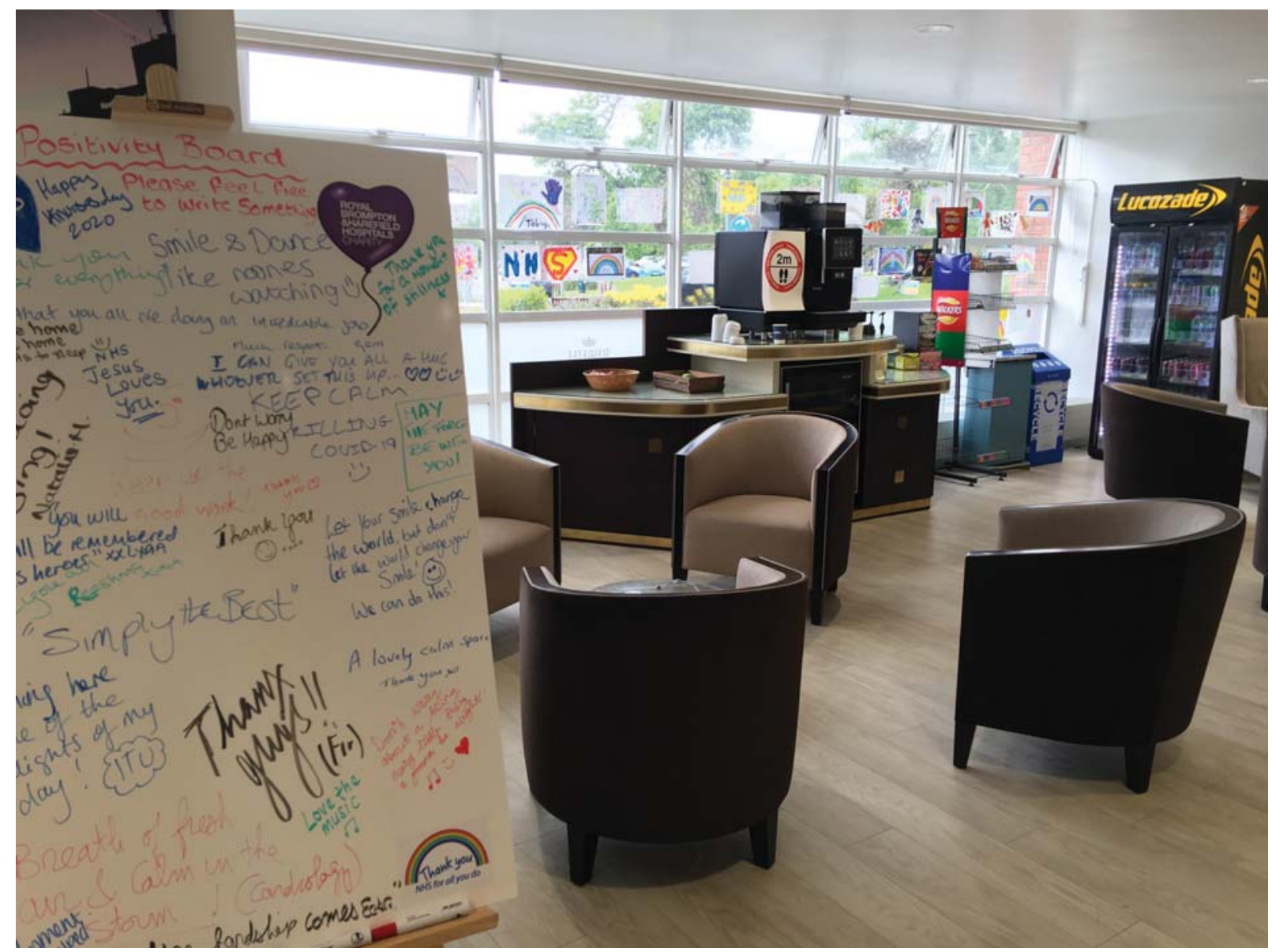

Fig. 3 Harefield Hospital wellbeing lounge (formally the private patient lounge); the institution during COVID-19. COVID-19, novel coronavirus disease 2019.

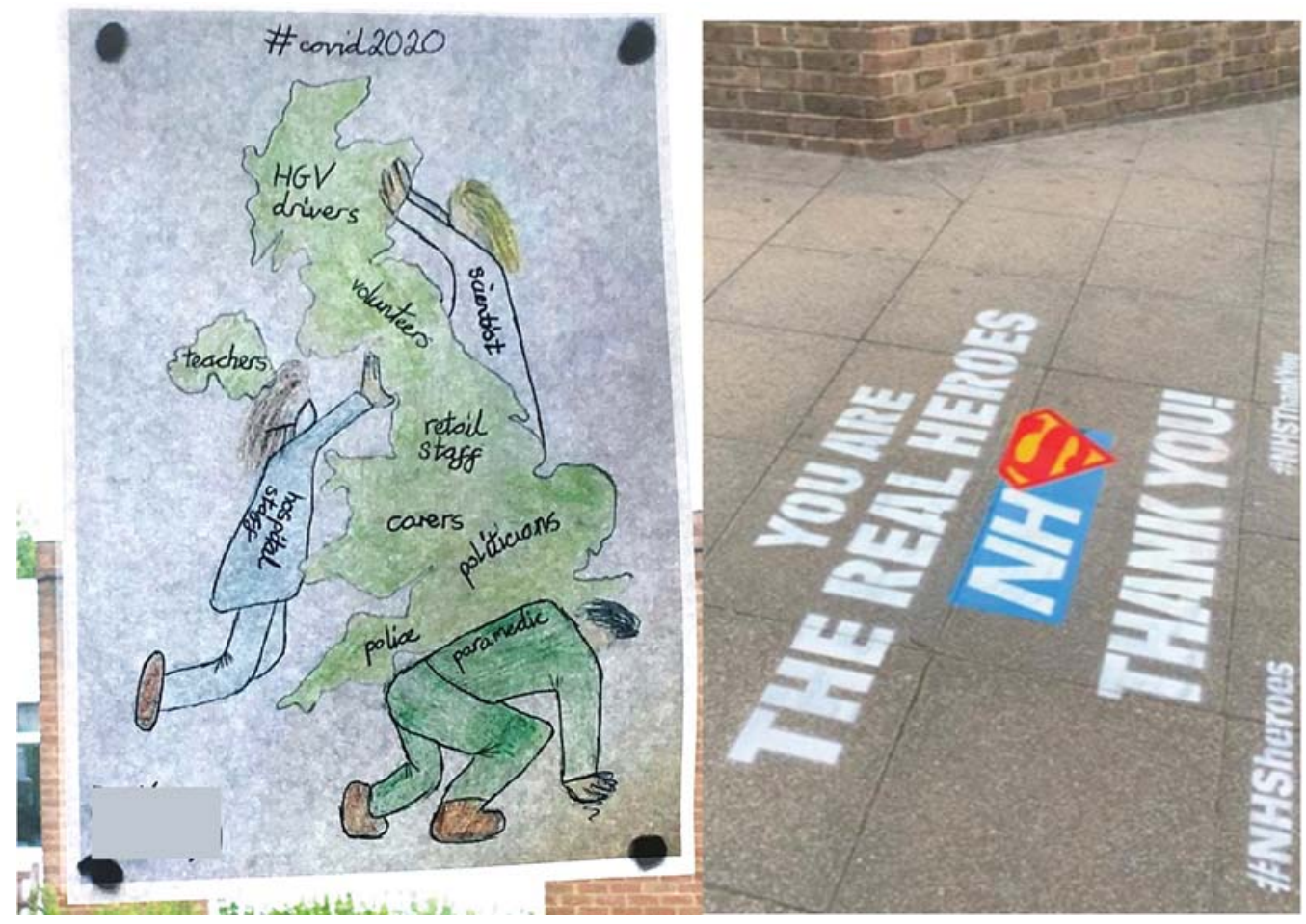

Fig. 4 Support on the streets and in hospital. 
cardiologists were involved which lead to an interdisciplinary exchange.

Practical training, indeed, had an impact on our formation. When new surgeons arrived, the usual groups had to rearrange themselves to support the other teams. However, it must be mentioned that we were in a lucky position to provide the cardiothoracic care through the COVID-19 crisis.

\section{If Crisis Lasts for Months, How Can We Continue Education?}

Ideally, the online teaching via conferences might be an easy way to follow research and examination-relevant topics regularly. It has the promising potential to grow by spreading through invitations to further experts putting the meetings in a more interdisciplinary light. It is also a good opportunity to make theoretical teaching finally mandatory not only in the own department but also by chairing a session, that is, once per month, with another cardiothoracic unit. Consultants can actively help by attending the meetings and mentor the speakers and presenters. This form of online teaching can be also a great opportunity for the young surgeons as the initiators to set up a nation-wide teaching format.

Practical training needs special attention. For those, who are working in departments cannot accept patients for operation, simulators become the only chance to keep up with manual practice. Again, these times remind us of the necessity of simulators that are not only available but also accredited by educational committees to avoid that training is postponed. Another alternative is the active exchange of trainees to other centers which might need a hand during operation, no matter if second or first assistance.

\section{What We Learned and What Will Stay}

... That in the first line, we are not only doctors, but also individuals. Simply the motivation to carry on with our daily work, lead to a new mindset, and the awareness how grateful we can be to perform our job. It is interesting how much we identify with this manual work which is connected to so much satisfaction, teamwork, and passion.

In the end, the crisis holds a chance for everybody individually and for the crowd to develop and change. The message is easy to summarize in one word: collaboration to foster and support future generations.

Conflict of Interest

None declared. 